\title{
Rhetoric In Advertising
}

\author{
Vu Xuan Doan ${ }^{*}$ \\ VNU International School, Building G7, 144 Xuan Thuy, Cau Giay, Hanoi, Vietnam
}

Received 18 April 2017

Revised 12 June 2017, Accepted 28 June 2017

\begin{abstract}
Advertising mobilizes many methods relevant to three fundamental elements of rhetoric such as Ethos, Pathos and Logos by using, for example rhetorical figures such as special images, unusual words, and arrangement of information leading to desirable deduction and strong emotion. Methods using images are more efficient than traditional ones using words. They are known as visual rhetoric. In television advertising, the most used rhetorical figures are repetition, hyperbole, metaphor, and comparison.
\end{abstract}

Keywords: Rhetoric, visual rhetoric, rhetorical figures, advertising.

\section{Introduction}

Advertising is primarily about reinforcing the brand image of current customers, finding new customers, and positively impacting consumer attitude. In other words, advertising aims to capture the customer's attention, make the impression unforgettable, and persuade consumers to buy the product. So how can advertising achieve this purpose? We can look at the tactics of advertising from the perspective of rhetoric.

Data and Research methods: This article looks into the study of rhetorical figures used in 200 randomly selected video clips on Vietnamese television. Based on widely accepted theory, the study conducted observations, categorization, and statistics to obtain a general overview of the operation of rhetorical figures in television advertising.

Objective and Research questions: The article aims to clarify the presence and the

\footnotetext{
${ }^{*}$ Tel.: 84-903265792.

Email: doanvx@isvnu.vn

https://doi.org/10.25073/2588-1116/vnupam.4093
}

importance of rhetoric in advertising. In the scope of this article, the research will focus on factors that affect consumers' emotion which are rhetorical figures. Thus, the research question will be: What are the most used rhetorical figures in television advertising?

Related works: There have been a number of authors in Vietnam such as Mai Xuân Huy [1], Nguyễn Kiên Trường [2] who have published books with relevant subject, and many foreign articles mentioning rhetoric in advertising. But such publications don't have the same purpose and research questions as this article.

\section{Some theoretical background}

2.1. An overview of the utilization of rhetoric in advertising

From the Aristotle era (384-322) BC, rhetoric has been valued. Initially, sages taught rhetoric to help citizens persuade their audience to secure their rights to democracy. By the first century, rhetoric began to be used in literature, 
to beautify speech, not merely to convince. Today, with its striking, convincing, and persuasive personality, rhetoric is used in business field to influence consumers' decisions. Rhetoric uses three basic elements dating back to the Aristotle era (384-322 BC). It's Ethos - related to the speaker's position, Pathos - related to emotions and Logos - related to the logic of discourse. Different from traditional rhetoric which only relied on words, advertising now harnesses the advantages of visual language combined with language to increase persuasion and save time.

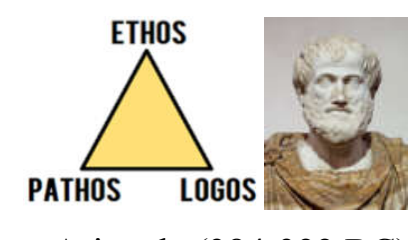

Aristotle (384-322 BC).

\subsection{Three basic elements of rhetoric utilized in advertising}

Ethos represents the speaker's position. The more prestigious the speaker, the better the position, the more persuasive the discourse. In advertising, we often see the appearance of celebrities involved in the introduction of a product. This implies that the information in the advertisements is from reputable sources, reliable, and of high quality. People attach images of these characters to the image of the product, etc.

Pathos is the emotionally responsible nature of speech, with regard to the ways in which the listener is attentive, impressed, and thereby increases the convincing effect. In advertising, the elements that make up Pathos include music and emotional images. For example, soothing music; optimistic, cheerful, and seductive images make viewers happy with the advertisement and so pleased with the product being introduced. Cheerful images and words make a special impression through the unusual expressions.

Logos shows the organization of the arguments that lead the listener to conclusions that benefit the discourse. These arguments may be in the form of figures, events, outstanding qualities as well as the association of events. All are presented in a logical sequence that drives the consumer in the way that the advertiser prescribes. Logos using images will have a stronger impact than words because images are more lively, understandable, and easier to remember than text. For example, models appearing in beautiful dresses or using beauty products which are seductive will convince consumers that they will be as in the figure of the models when using the advertised product. The introduction of images of many people using the same product can also easily make consumers attracted.

\subsection{Visual rhetoric}

Traditionally, rhetoric is considered to be the domain of spoken language. However, the use of images to convey information to convince viewers is also seen as eloquence, especially in advertising. Since 1959, advertisements with images have grown steadily in the United States. In Vietnam, with the development of market economy, advertisements with images have become familiar. Bulmer \& Buchanan-Oliver [3] defined "Visual rhetoric can be described as a form of communication that uses images for creating meaning or constructing an argument. Hence, an analysis of Visual rhetoric views how images work alone and collaborated with other elements to create an argument designed for moving a specific audience. "

Images can deliver simultaneously significant elements like colors, lighting, expression and gestures. Hence, visual rhetoric can help avoid the use of cumbersome words. The language of images can quickly convey the message of the advertisements, promoting the positive thoughts in the audience. Visual rhetoric also has disadvantages. Advertisements become difficult to understand in the presence of overwhelming, and fast-paced images that make viewers unable to establish a connection 
between them. Characters are sometimes only impressive and unrelated to the product. The presence of these characters can be confusing, unsettling, or overwhelming that the audience is attracted to the characters and forget about the product. On a case-by-case basis, words need to be introduced appropriately to emphasize a message, and to clarify a meaning.

\subsection{Rhetorical figures used in advertisements}

According to Oxford Dictionary [4], rhetorical figures are "Any of the forms of expression which give beauty, variety, force, etc., to a composition in accordance with the theory and principles of rhetoric, as metaphor, metonym, hyperbole, etc"

The use of "rhetorical figures" relates the most to the Pathos element. Rhetorical figures "itself" is not meant to convey semantic information. It focuses primarily on the implications of the way information is conveyed". For example, the repetition method does not yield new information but in fact only constitutes an unforgettable impression, a persistent obsession about the subject introduced.

Although mainly related to Pathos, the rhetorical figures affected the entire discourse and were studied from the smallest manifestations from timbre to the structures of discourse. Rhetorical figures, although not receiving much attention in teaching literature as before, flourished in commercial advertising.

Visual rhetoric uses images of people or objects, beyond their familiar image to impress, to attract attention, and to persuade viewers. Visual rhetoric can manipulates images in an unusual way to produce the effects of implicit, exorbitant, dual, etc. similar to traditional methods using speech. The images, when properly set up, make viewers have inferences about the implied information about the product.

There are quite a few rhetorical figures used in advertising. Figures in visual rhetoric can be distinguished and classified similar to traditional figures. Accordingly, we have names such as repetition, exaggeration, comparison, duality, allegory, etc. Let us consider the presence and frequency of these figures in advertising.

\section{Data collection}

This statistics is the results of a review of 200 randomly selected video clips on Vietnamese television, including 123 short advertisements for 15 seconds, 74 advertisements for 30-40 seconds; 1 very short advertisement with 7 seconds; an advertisement that is longer than 1 minute and a special advertisement of 2 minutes. These advertisements relate to many types of products and to all consumers, including nutrition foods, functional foods, medicines, toys, shower gel, air conditioning, motorcycles, cars ... All rhetorical figures in the form of images, words, and sounds are noted. The results are as follow:

\section{Findings and discussion}

\subsection{Frequency of rhetorical figures in advertising}

The results showed that repetition, hyperbole, and comparison (including metaphor) were used the most, accounting for $99 \%, 73 \%$ and $70 \%$, respectively. Other methods have much lower frequency of less than or equal to $32 \%$. This shows that the primary concern of advertisers is to make the viewer remember the product in the most common, most easily understood form of expression. The next common methods are ellipsis, assonance, and allegories which accounted for $32 \%, 25 \%$ and $20 \%$, respectively. Methods such as personification and metonymy represent a small proportion of $15 \%$ and $14 \%$. Rarely used measures are adaptation, rhetorical questions, discontinuity and parallelism that accounted for only 3 to $4 \%$ of the 200 advertisements reviewed. 
Table 1. Frequency of rhetorical figures

\begin{tabular}{|c|c|c|c|c|c|}
\hline \multirow{2}{*}{ No. } & \multirow{2}{*}{ Figures } & \multirow{2}{*}{ Frequency } & \multicolumn{2}{|l|}{ Form } & \multirow{2}{*}{$\%$ of grand total } \\
\hline & & & Word / Sound & Image & \\
\hline 1 & Repetition & 198 & + & + & $99 \%$ \\
\hline 2 & Hyperbole & 145 & + & + & $73 \%$ \\
\hline 3 & $\begin{array}{l}\text { Metaphor and } \\
\text { Comparison }\end{array}$ & 139 & + & + & $70 \%$ \\
\hline 4 & Ellipsis & 64 & + & & $32 \%$ \\
\hline 5 & Assonance & 50 & + & & $25 \%$ \\
\hline 6 & Allegory & 39 & & + & $20 \%$ \\
\hline 7 & Personification & 30 & + & + & $15 \%$ \\
\hline 8 & Metonymy & 27 & + & + & $14 \%$ \\
\hline 9 & Adaptation & 8 & + & + & $4 \%$ \\
\hline 10 & Rhetorical Question & 6 & + & & $3 \%$ \\
\hline 11 & Rupture & 6 & + & + & $3 \%$ \\
\hline 12 & Parallelism & 5 & + & & $3 \%$ \\
\hline
\end{tabular}

\subsection{Three most usual rhetorical figures in advertising}

\subsubsection{Repetition}

Repetition of image, words, sentences, are presented in $99 \%$ of the advertisements. Duplicate images have the largest proportion with $81 \%$ of the advertisements, followed by word repetition in $77 \%$ of the advertisements and sentence repetition with $17 \%$. Repeated images are images of the product. Repeated words are usually words that refer to a product's name, or to a particular characteristic of the product. Repeated sentences emphasize the nature of the product.

Table 2. Repetition

\begin{tabular}{|c|c|c|c|}
\hline No. & Description & Frequency & $\begin{array}{l}\% \text { of grand } \\
\text { total }\end{array}$ \\
\hline 1. & $\begin{array}{l}\text { With } \\
\text { repetition }\end{array}$ & 198 & $99 \%$ \\
\hline 2. & Image & 162 & $81 \%$ \\
\hline 3. & Word & 154 & $77 \%$ \\
\hline 4. & Sentence & 33 & $17 \%$ \\
\hline
\end{tabular}

Repetition is a tactic of repeating a key message related to the product, to make consumers impressed, to remember to the level of obsession with the product. If there is no repetition, information on the product is likely to drift away, and the advertisement would not work. This explains why repetition is used in most advertisements and only differs in degree and method. Repetition only repeats the original information without change or modification.

\subsubsection{Hyperbole}

Hyperbole is a rhetoric method of impression by over-emphasizing, overexaggerating a characteristic of the product. Exaggerated comparison over conventional imagination is also considered hyperbole. Since advertisement has a very short duration, it tries to impress immediately by using hyperbole. This method is utilized in $73 \%$ of advertisements reviewed. Hyperbole in image is present in $53 \%$ of the advertisements and the hyperbole in words $35 \%$ of the ads. The advertisements having hyperbole in both images and words account for $15 \%$ of the advertisements.

Table 3. Hyperbole

\begin{tabular}{|c|c|c|c|}
\hline No & Description & Frequency & $\begin{array}{l}\% \text { of grand } \\
\text { total }\end{array}$ \\
\hline 1 & $\begin{array}{l}\text { With } \\
\text { hyperbole }\end{array}$ & 145 & $73 \%$ \\
\hline 2 & Image & 105 & $53 \%$ \\
\hline 3 & Word & 69 & $35 \%$ \\
\hline 4 & $\begin{array}{l}\text { Image and } \\
\text { word }\end{array}$ & 30 & $15 \%$ \\
\hline
\end{tabular}




\subsubsection{Comparison and Metaphor}

Metaphor and comparison are solid methods to highlight the strengths of the product. They are comprehensive and persuasive advertising methods and are used in $70 \%$ of the advertisements reviewed. Metaphor is presented in $58 \%$ of advertissments while comparison is only in $25 \%$.

Table 4. Comparison and Metaphor

\begin{tabular}{llll}
\hline No. & Description & Frequency & $\begin{array}{l}\% \\
\text { grand } \\
\text { total }\end{array}$ \\
\hline 1 & Total & 139 & $70 \%$ \\
2 & Metaphor & 115 & $58 \%$ \\
3 & $\begin{array}{l}\text { Comparison } \\
\text { Metaphor }\end{array}$ & 49 & $25 \%$ \\
4 & $\begin{array}{l}\text { and } \\
\text { comparison }\end{array}$ & 26 & $13 \%$ \\
5 & $\begin{array}{l}\text { Visual } \\
\text { metaphor }\end{array}$ & 85 & $43 \%$ \\
\hline
\end{tabular}

Metaphor is a comparison without using words for comparison. One can use conventional metaphor, which are commonly used metaphor in the language community, or create a new metaphorical expression. Jeong, S [5] found that "Visual metaphors are similar to verbal metaphors yet visual metaphors can also be characterized as visual argumentation in that it employs the syntactic structure of visual persuasion".

Comparison is the comparative use of words for comparisons such as "as", "like", etc. So this method is mainly in the text. For example, advertising OmoMatic washing powder with the words "Clean as washed by mother's own hand" without the text displayed on the screen; Sometimes the words are accompanied by letters displayed on the screen as in the advertisement of Castrol Power 1 Scooter Lubricants, the words "Blazing like new" is repeated in a joyful song, catchy rhythm creates an optimistic sense for product use. Similar to the Nescafe advertisement, there is one final quote: "What a bold comparison of Nestcafé" with the line that appears with the brand image.
In advertising, visual metaphor is a very common rhetoric, which presents in $43 \%$ of advertisements. According to McQuarrie and Mick [6], Bulmer and Buchanan-Oliver [3], image metaphor is recognizable and evokes more complex cognitive elaboration in audience's mind than literal image. Like other rhetorical figures, visual metaphors are especially effective because they convey a lot of information that is less wordy, less time consuming. As an implicit comparison, the hidden information can be easily seen by viewers thanks to the ingenious metaphor of the advertiser and the knowledge of the customer.

\section{Conclusion}

The result of this research confirms the presence and the importance of rhetoric in advertising. This study has showed that rhetoric methods use a large number of rhetorical figures to influence the emotions of consumers. The most used rhetorical figures in television advertissments are repetition, hyperbole, metaphor, and comparison. These rhetorical devices are mainly in the form of images.

Characterized by a discourse with the purpose of persuasion, advertising uses the rhetorical device, especially visual rhetoric, to psychologically influence viewers. Rhetorical figures in visual rhetoric are powerful tools that are used frequently to promote product value and leave strong impression, to manifest positive thought in viewers to remember the product. Rhetorical figures in advertising are varied and are used in a much more flexible way than words in text. The identification and understanding of the function of the rhetorical figures will help those trained in the field of business.

This is only an initial study to identify a number of factors that affect the psychology of the consumer. It is hoped that more thorough, detailed research will be available for specific recommendations. 


\section{References}

[1] Mai Xuân Huy, [Advertising language in light of communication theory] Ngôn ngữ quảng cáo dưới ánh sáng của lý thuyết giao tiếp, NXB Khoa học Xã hội, Hà Nội, 2005.

[2] Nguyễn Kiên Trường, [Advertising and advertising language] Quảng cáo và ngôn ngữ quảng cáo, NXB Xã hội, Thành phố Hồ Chí Minh, 2004.

[3] S. Bulmer, \& M. Buchanan-Olivier, Visual rhetoric and global advertising imagery. Journal of Marketing Communications, 12 (2006) 49.
[4] English Oxford Living English Dictionary. Source:

https://en.oxforddictionaries.com/definition/rhet orical_figure

[5] S. Jeong, Visual metaphor in advertising: Is the persuasive effect attributable to visual argumentation or metaphorical rhetoric? Journal of Marketing Communications, 14 (2008) 59.

[6] E. McQuarrie, \& D. Mick, Visual rhetoric in advertising: Text-interpretive, experimental, and reader-response analyses. Journal of Consumer Research, 26 (1999) 37 